REVIEW

\title{
Using nitric oxide to treat tendinopathy
}

\author{
George A C Murrell
}

Br J Sports Med 2007;41:227-231. doi: 10.1136/bjsm.2006.034447

Nitric oxide (NO) is a small free radical generated by a family of enzymes, the nitric oxide synthases (NOSs). Following injury to a tendon, NO is induced by all three isoforms of NOS and NOS activity is also upregulated in tendinopathy. In animal models when NOS activity is inhibited by competitive inhibitors of NOS, tendon healing is reduced. When additional $\mathrm{NO}$ is added, tendon healing is enhanced. In humans, in three randomised clinical trials, we have shown that NO delivered via a transdermal patch enhances the subjective and objective recovery of patients with tennis elbow, Achilles tendinosis and supraspinatus tendinosis.

$\mathrm{N}$ itric oxide (NO) is a small soluble gas synthesised by a family of enzymes, the nitric oxide synthases (NOSs). Like other free radicals, in large doses NO is toxic. In smaller, physiological doses, however, it acts as a messenger molecule.

The family of NOSs consists of three isoforms regulated by a number of cofactors. eNOS (originally found in endothelial cells ${ }^{1}$ ) and bNOS (originally identified in brain and neuronal tissue ${ }^{2}$ ) are constitutive, low-output isoforms important in blood pressure regulation and memory. Inducible NOS (iNOS) is a high-output isoform important in host defence. ${ }^{3}{ }^{4}$

\section{NOS ACTIVITY FOLLOWING TENDON INJURY}

There is little NOS activity in a normal, uninjured tendon. Following division, however, we found a significant (approximately fivefold) increase in NOS activity within the healing tendon in rat Achilles $^{5}$ and supraspinatus tendons. The activity peaks at day 7 and returns to baseline at day 14. This activity was inhibitable by an NOS inhibitor $\left(\mathrm{N}^{\mathrm{G}}\right.$ monomethyl-L-arginine). All three NOS isoforms were expressed following rat Achilles tendon division. Four days after injury, there were increases in the steady-state levels of mRNA and protein for all 3 NOS isoforms, with peaks for iNOS (23-fold increase) at days 4 and 7 , eNOS (24-fold increase) at day 7 and bNOS (7-fold increase) at day $21 .^{67}$

\section{RAT ROTATOR CUFF TENDON HEALING}

We also examined NOS expression in an acute rotator cuff tendon model in the rat by creating a defect in the supraspinatus tendon with a $3 \mathrm{~mm}$ diameter biopsy punch. In this model, all three NOS isoforms as determined by competitive reverse transcriptase-PCR were expressed. The expression profile was slightly different from that of healing rat Achilles tendon, with bNOS expression maximum on day 4 , eNOS on day 7 and iNOS on day $7 .^{8}$

\section{RAT ROTATOR CUFF TENDON OVERUSE MODEL}

In an exercise overuse model of tendon degeneration in the rat, ${ }^{910}$ we found that iNOS, eNOS and bNOS mRNAs were overexpressed in the supraspinatus tendon of rats subjected to treadmill running at 14 days. ${ }^{11}$ These results suggest that NOS activity is induced as a result of tendon injury in this model, and/or that expression of NOS is a part of supraspinatus tendinopathy.

HUMAN ROTATOR CUFF TENDON INJURY During surgical repair of the rotator cuff in humans, the edges of the torn tendon are excised and discarded. We have evaluated these samples and found that NOS enzyme activity was detectable in 7 of 10 human rotator cuff tendon samples. mRNA expression was demonstrated for iNOS and eNOS isoforms in each sample examined, whereas bNOS mRNA was detectable in 3 of 8 samples. ${ }^{12}$ These results indicate that a similar phenomenon of NOS upregulation following injury occurs in humans as in rats.

\section{WHERE DOES NO COME FROM?}

In the rat Achilles tendon model, the first isoform to appear was iNOS, followed by eNOS and then bNOS. As one would expect, iNOS was expressed in macrophage-like cells and eNOS was found in endothelial cells. ${ }^{6}$ Interestingly, all three isoforms were expressed in fibroblast-like cells, again in a temporal fashion, with iNOS being expressed first (days 4-7), followed by eNOS (days 4-14) and bNOS (days 14-21).

\section{IS NOS EXPRESSION IMPORTANT TO TENDON HEALING?}

We fed rats a competitive NOS inhibitor (N-nitroL-arginine methyl ester) and found that rats taking this inhibitor had significantly reduced healing of their Achilles tendons compared with rats drinking its inactive enantiomer (N-nitro-D-arginine methyl ester). There was a $50 \%$ reduction in cross-sectional area of the Achilles tendon at day 7, and a corresponding $24 \%$ reduction in the failure load of the rat Achilles tendon constructs. ${ }^{5}$ We have also performed experiments on iNOS knockout mice and concluded that iNOS alone is not responsible for the beneficial effects of $\mathrm{NO}$ on tendon healing. ${ }^{13}$

\section{WHAT ROLES DOES NO PLAY IN TENDON HEALING?}

The experiments on animals using NOS inhibitors show that NO is important for the volume of tissue synthesised during tendon healing (fig 1). NO is likely to be important in a number of processes, including local blood flow and host defence. Work in our laboratory has identified NO to be important in collagen synthesis. ${ }^{14}$ Cultured human rotator cuff tendon cells, when exposed to exogenous NO in the form of S-nitro- $\mathrm{N}$-acetyl penicillamine and when transfected with the iNOS gene via an adenovirus

Abbreviations: $\mathrm{NO}$, nitric oxide; NOS, nitric oxide synthase; bNOS, brain NOS; eNOS, endothelial NOS; GTN, glyceryl trinitrate; iNOS, inducible NOS 


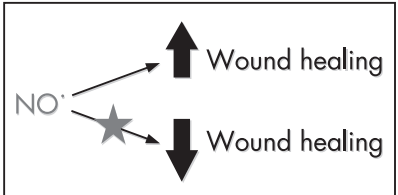

Figure 1 Schematic diagram of the overall effects of the addition and inhibition of nitric oxide (NO) on tendon healing. vector, incorporated more collagenase-sensitive ${ }^{3} \mathrm{H}$-proline in their matrix. This increased collagen synthesis was inhibited by an NOS inhibitor.

We used microarray analysis to elucidate global gene expression after transfection with iNOS in tenocytes isolated from the injured rotator cuff tendons of humans. The expression of a wide range of genes was affected by NO, with many activated genes having known roles in healing. Of particular significance was that NOS overexpression stimulated the transcription and translation of a range of extracellular matrix genes important to the structure of connective tissues such as tendons, including collagen type I $\alpha$ l, collagen type III $\alpha$, collagen IV $\alpha 5$, biglycan, decorin, laminin and matrix metalloproteinase 10 . These genes were also shown to respond to stimulation by the NO donor S-nitroso- $\mathrm{N}$-acetyl-penicillamine in a dose-dependent manner. ${ }^{15}$ We also showed that varying levels of NO significantly affect cellular adhesion in tenocytes, a critical process during tendon repair. ${ }^{15}$

In our rat model, we delivered NO via flurbiprofen, a nonspecific cyclo-oxygenase inhibitor and via NO-paracetamol. In both experiments, the addition of $\mathrm{NO}$ had a protective or beneficial effect on collagen organisation, tendon healing failure load and stress (load/area). ${ }^{16}{ }^{17}$ These rat results are consistent with cell culture findings for human tendon cells

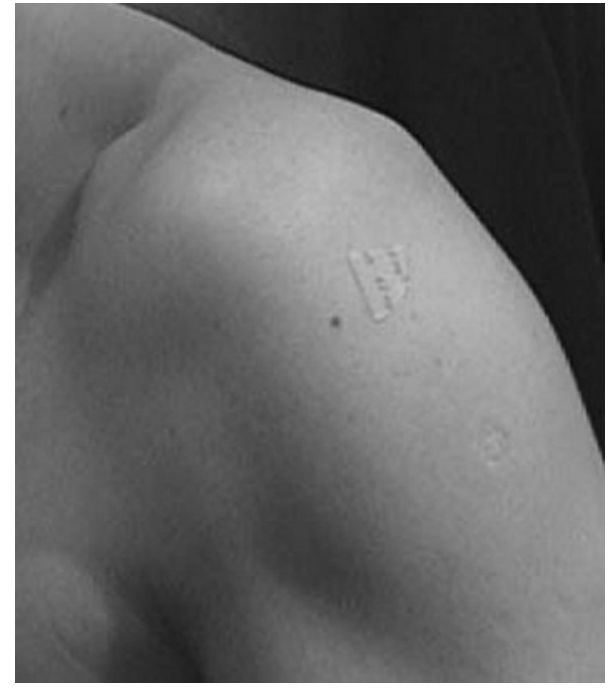

Figure 2 Application of a glyceryl trinitrate (GTN) patch to the shoulder for supraspinatus tendinosis.

where NO enhanced collagen synthesis, and with the results from the clinical trials described below.

\section{CLINICAL TRIALS}

To determine whether additional NO might enhance tendon healing in humans, we conducted three randomised doubleblind clinical trials. These trials involved the application of a

Table 1 Genes upregulated or downregulated in cultured tendon cells following exposure to nitric oxide ${ }^{15}$

\begin{tabular}{|c|c|c|}
\hline Primary function & Gene & $\begin{array}{l}\text { Effect on gene } \\
\text { regulation }\end{array}$ \\
\hline \multirow{4}{*}{ Apoptosis } & Immediate early response 3 & Up \\
\hline & Jun $D$ & Up \\
\hline & COP9 constitutive photomorphogenic homologue subunit 8 & Up \\
\hline & Growth arrest-specific 2 like 1 & Down \\
\hline \multirow[t]{2}{*}{ Cell adhesion/communication } & Protocadherin $\alpha 6$ & Up \\
\hline & Catenin (cadherin-associated protein), $\delta 2$ & Down \\
\hline Cell cycle control & Cell division cycle 34 & Down \\
\hline \multirow{5}{*}{ Cell growth and/or maintenance } & Potassium inwardly rectifying channel, subfamily J, member 8 & Up \\
\hline & Translocated promoter region (to activated MET) & Up \\
\hline & Human cellular proto-oncogene (c-mer) & Down \\
\hline & TGF- $\beta$ inducible early protein & Down \\
\hline & S100 calcium-binding protein $\mathrm{A} 11$ & Up \\
\hline \multirow{8}{*}{ Extracellular matrix/regulation } & Matrix metalloproteinase 10 (stromelysin 2) & Down \\
\hline & Collagen type I, $\alpha 1$ & Down \\
\hline & Decorin & Down \\
\hline & Laminin B2 & Down \\
\hline & Biglycan & Down \\
\hline & Collagen type III, $\alpha 1$ & Down \\
\hline & Collagen type IV, $\alpha 5$ & Up \\
\hline & Microfibrillar-associated protein 3-like & Up \\
\hline Oxidative stress resistance & Oxidation resistance 1 & Up \\
\hline \multirow[t]{11}{*}{ Signal transduction } & TNF receptor-associated factor 5 & Up \\
\hline & Rho GTPase-activating protein 4 & Up \\
\hline & Interleukin 18 receptor 1 & Up \\
\hline & IGF-II mRNA-binding protein 3 & Up \\
\hline & SMA D5 & Up \\
\hline & Phospholipase DI, phophatidylcholine-specific & Up \\
\hline & $\begin{array}{l}\text { Tyrosine 3-mono-oxygenase/tryptophan 5-mono-oxygenase activation } \\
\text { protein, కpolypeptide }\end{array}$ & Up \\
\hline & Ras suppressor protein 1 & Up \\
\hline & Interferon regulatory factor 3 & Up \\
\hline & A kinase (PRKA) anchor protein 10 & Up \\
\hline & Mitogen-activated protein kinase 7 & Down \\
\hline Transport, cell growth and/or maintenance & Solute carrier family 22 & Up \\
\hline
\end{tabular}

COP, coat protein complex; GTPase, guanosine triphosphatase; IGF, insulin-like growth factor; MET, methionine; PRKA, protein kinase Aanchoring; SMA, smooth muscle actin; TGF, transforming growth factor; TNF, tumour necrosis factor. 
Table 2 Effects of glyceryl trinitrate $1.25 \mathrm{mg} /$ day through transdermal patch and rehabilitation versus rehabilitation alone on tennis elbow (adapted from Paoloni et a ${ }^{19}$ )

\begin{tabular}{|c|c|c|c|}
\hline Week & Active & Placebo & p Value \\
\hline \multicolumn{4}{|c|}{ Pain with activity-all patients } \\
\hline 2 & 2.1 & 2.3 & 0.31 \\
\hline 6 & 1.8 & 1.9 & 0.57 \\
\hline 12 & 1.5 & 1.6 & 0.61 \\
\hline 24 & 1.3 & 1.5 & 0.56 \\
\hline \multicolumn{4}{|c|}{$\begin{array}{l}\text { Pain with activity-bilateral patients excluded } \\
\qquad(\mathrm{n}=31) \\
(\mathrm{n}=37)\end{array}$} \\
\hline 2 & 2.1 & 2.4 & 0.11 \\
\hline 6 & 1.8 & 1.9 & 0.57 \\
\hline 12 & 1.5 & 1.6 & 0.72 \\
\hline 24 & 1.3 & 1.5 & 0.43 \\
\hline \multicolumn{4}{|c|}{ Tenderness - by elbow } \\
\hline 2 & 1.0 & 1.1 & 0.25 \\
\hline 6 & 0.7 & 1.1 & 0.014 \\
\hline 12 & 0.7 & 1.1 & 0.006 \\
\hline 24 & 0.5 & 1.0 & 0.014 \\
\hline \multicolumn{4}{|c|}{$\begin{array}{l}\text { Tenderness-bilateral data averaged } \\
\qquad(n=35)\end{array}$} \\
\hline 2 & 1.0 & 1.2 & 0.08 \\
\hline 6 & 0.6 & 1.1 & 0.010 \\
\hline 12 & 0.6 & 1.1 & 0.003 \\
\hline 24 & 0.5 & 1.0 & 0.008 \\
\hline \multicolumn{4}{|c|}{$\begin{array}{l}\text { Tenderness-bilateral patients excluded } \\
\qquad(\mathrm{n}=31)\end{array}$} \\
\hline 2 & 0.9 & 1.2 & 0.037 \\
\hline 6 & 0.8 & 1.3 & 0.008 \\
\hline 12 & 0.8 & 1.3 & 0.002 \\
\hline 24 & 0.6 & 1.1 & 0.008 \\
\hline \multicolumn{4}{|c|}{$\begin{array}{l}\text { Change from baseline in total work- by elbow } \\
\qquad(n=39) \quad(n=41)\end{array}$} \\
\hline 2 & 8.9 & -1.8 & 0.048 \\
\hline 6 & 21.6 & 5.6 & 0.007 \\
\hline 12 & 23.0 & 6.5 & 0.019 \\
\hline 24 & 35.9 & 15.4 & 0.019 \\
\hline \multicolumn{4}{|c|}{$\begin{array}{l}\text { Change from baseline in total work - all patients - bilateral data averagec } \\
\qquad(n=35)\end{array}$} \\
\hline 2 & 9.8 & -2.0 & 0.036 \\
\hline 6 & 23.1 & 6.5 & 0.007 \\
\hline 12 & 23.2 & 7.3 & 0.027 \\
\hline 24 & 38.5 & 17.1 & 0.020 \\
\hline \multicolumn{4}{|c|}{$\begin{array}{l}\text { Change from baseline in total work-bilateral patients excluded } \\
\qquad(\mathrm{n}=31) \\
(\mathrm{n}=37)\end{array}$} \\
\hline 2 & 11.0 & -2.4 & 0.028 \\
\hline 6 & 25.0 & 7.4 & 0.007 \\
\hline 12 & 23.4 & 8.0 & 0.044 \\
\hline 24 & 41.9 & 18.9 & 0.019 \\
\hline \multicolumn{4}{|c|}{$\begin{array}{l}\text { Pain at night-all patients } \\
\qquad(n=35)\end{array}$} \\
\hline 2 & 1.2 & 1.4 & 0.28 \\
\hline 6 & 0.9 & 1.2 & 0.20 \\
\hline 12 & 0.9 & 1.1 & 0.33 \\
\hline 24 & 0.7 & 0.8 & 0.44 \\
\hline \multicolumn{4}{|c|}{$\begin{array}{l}\text { Pain at night-bilateral patients excluded } \\
\qquad(\mathrm{n}=31) \quad(\mathrm{n}=37)\end{array}$} \\
\hline 2 & 1.1 & 1.4 & 0.13 \\
\hline 6 & 0.9 & 1.2 & 0.24 \\
\hline 12 & 0.9 & 1.1 & 0.38 \\
\hline 24 & 0.6 & 0.8 & 0.39 \\
\hline \multicolumn{4}{|c|}{$\begin{array}{l}\text { Pain at rest-all patients } \\
\qquad(n=35)\end{array}$} \\
\hline 2 & 1.1 & 1.2 & 0.84 \\
\hline 6 & 0.8 & 1.0 & 0.32 \\
\hline 12 & 0.9 & 1.0 & 0.54 \\
\hline 24 & 0.9 & 1.0 & 0.66 \\
\hline \multicolumn{4}{|c|}{$\begin{array}{l}\text { Pain at rest-bilateral patients excluded } \\
\qquad(\mathrm{n}=31)\end{array}$} \\
\hline 2 & 1.0 & 1.1 & 0.56 \\
\hline 6 & 0.8 & 1.1 & 0.27 \\
\hline 12 & 0.9 & 1.0 & 0.69 \\
\hline 24 & & & 0.67 \\
\hline \multicolumn{4}{|c|}{$\begin{array}{l}\text { Change from baseline in peak force- by elbow } \\
\qquad(n=39) \quad(n=41)\end{array}$} \\
\hline 2 & 1.3 & 0.0 & 0.06 \\
\hline 6 & 2.5 & 0.8 & 0.016 \\
\hline 12 & 2.6 & 0.6 & 0.020 \\
\hline
\end{tabular}

\begin{tabular}{|c|c|c|c|}
\hline Week & Active & Placebo & $p$ Value \\
\hline 24 & 3.4 & 1.4 & 0.025 \\
\hline \multicolumn{4}{|c|}{$\begin{array}{l}\text { Change from baseline in peak force-all patients - bilateral data averagec } \\
\qquad(n=35) \\
\qquad(n=39)\end{array}$} \\
\hline 2 & 1.4 & -0.01 & 0.041 \\
\hline 6 & 2.6 & 0.9 & 0.015 \\
\hline 12 & 2.6 & 0.7 & 0.024 \\
\hline 24 & 3.7 & 1.6 & 0.024 \\
\hline \multicolumn{4}{|c|}{$\begin{array}{l}\text { Change from baseline in peak force-bilateral patients excluded } \\
\qquad(n=31)\end{array}$} \\
\hline 2 & 1.6 & -0.1 & 0.027 \\
\hline 6 & 2.8 & 1.0 & 0.016 \\
\hline 12 & 2.6 & 0.8 & 0.036 \\
\hline 24 & 4.1 & 1.8 & 0.021 \\
\hline
\end{tabular}

commercially available NO delivery system (glyceryl trinitrate (GTN) patches) and a placebo version of the same patch. These patches were applied over the area of tenderness for three conditions: tennis elbow, Achilles tendinosis and supraspinatus tendinosis (fig 2). A total of 53-86 patients were randomised to two groups in each of the trials. In each trial, the active group received continuous topical NO donation ( $1.25 \mathrm{mg} / 24 \mathrm{~h}$ GTN) and the placebo group received the identical patch without GTN. The

Table 3 Effects of glyceryl trinitrate $1.25 \mathrm{mg} /$ day through transdermal patch and rehabilitation versus rehabilitation alone in patients with Achilles tendonitis (adapted from Paoloni et $a^{(18)}$

\begin{tabular}{|c|c|c|c|}
\hline Week & Active & Placebo & p Value \\
\hline \multicolumn{4}{|c|}{ Pain with activity-all patients } \\
\hline 2 & 1.4 & 1.6 & 0.43 \\
\hline 6 & 1.1 & 1.4 & 0.22 \\
\hline 12 & 0.9 & 1.4 & 0.09 \\
\hline 24 & 0.6 & 1.0 & 0.15 \\
\hline \multicolumn{4}{|c|}{ Pain at rest-all patients } \\
\hline & $(n=28)$ & $(n=33)$ & \\
\hline 2 & 1.2 & 1.1 & 0.70 \\
\hline 6 & 0.9 & 1.1 & 0.47 \\
\hline 12 & 0.9 & 1.1 & 0.31 \\
\hline 24 & 0.8 & 0.9 & 0.58 \\
\hline \multicolumn{4}{|c|}{ Pain at night-all patients } \\
\hline & $(n=27)$ & $(n=33)$ & \\
\hline 2 & 1.5 & 1.7 & 0.41 \\
\hline 6 & 1.0 & 1.2 & 0.27 \\
\hline 12 & 0.6 & 0.9 & 0.058 \\
\hline 24 & 0.6 & 0.7 & 0.57 \\
\hline \multicolumn{4}{|c|}{ Pain on hopping-by heel } \\
\hline & $(n=37)$ & $(n=44)$ & \\
\hline 2 & 3.2 & 3.2 & 0.98 \\
\hline 6 & 2.9 & 3.1 & 0.68 \\
\hline 12 & 2.3 & 3.0 & 0.10 \\
\hline 24 & 1.2 & 2.1 & 0.023 \\
\hline \multicolumn{4}{|c|}{ Tenderness - all patients } \\
\hline & $(n=29)$ & $(n=33)$ & \\
\hline 2 & 1.7 & 1.7 & 0.75 \\
\hline 6 & 1.4 & 1.3 & 0.68 \\
\hline 12 & 0.8 & 1.3 & 0.055 \\
\hline 24 & 0.7 & 0.7 & 0.99 \\
\hline \multicolumn{4}{|c|}{$\begin{array}{l}\text { Change from baseline in total work- by heel } \\
(n=36) \\
(n=42)\end{array}$} \\
\hline 2 & 12.1 & 12.3 & 0.49 \\
\hline 6 & 12.9 & 13.2 & 0.66 \\
\hline 12 & 13.5 & 13.6 & 0.90 \\
\hline 24 & 14.9 & 13.6 & 0.10 \\
\hline \multicolumn{4}{|c|}{$\begin{array}{l}\text { Change from baseline in peak force- by heel } \\
\qquad(\mathrm{n}=36) \\
(\mathrm{n}=41)\end{array}$} \\
\hline 2 & 2.2 & 2.2 & 0.41 \\
\hline 6 & 2.4 & 2.4 & 0.54 \\
\hline 12 & 2.6 & 2.4 & 0.30 \\
\hline 24 & 2.9 & 2.5 & 0.010 \\
\hline
\end{tabular}


Table 4 Effects of glyceryl trinitrate $1.25 \mathrm{mg} /$ day through transdermal patch and rehabilitation versus rehabilitation alone in patients with supraspinatus tendinopathy (adapted from Paoloni et al $^{20}$ )

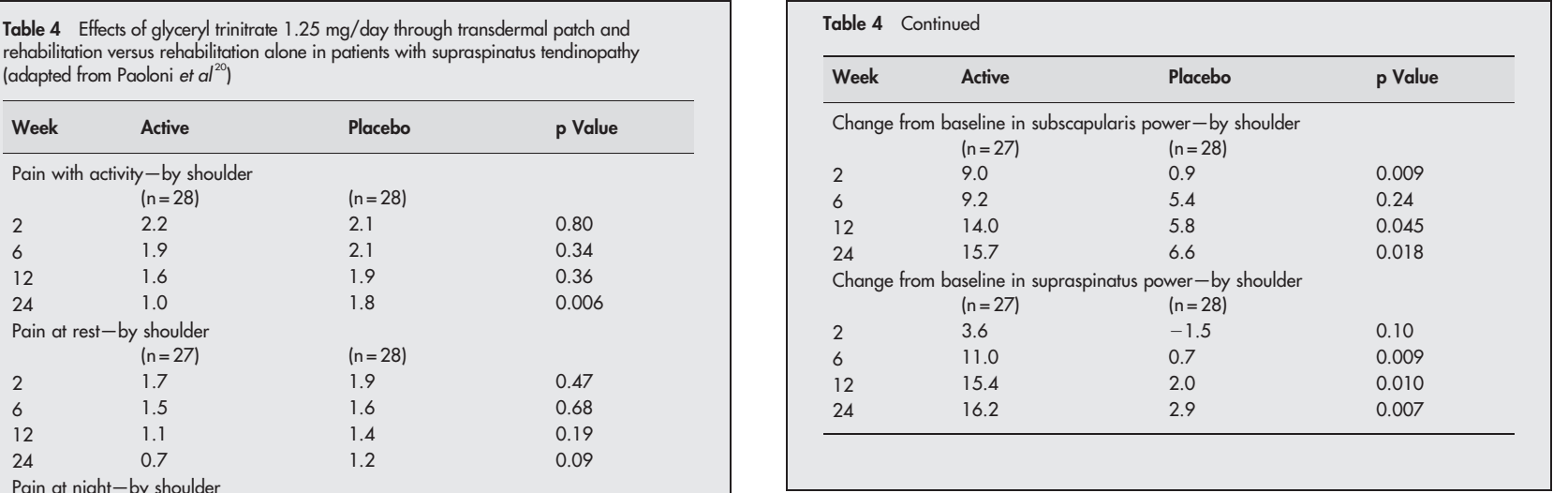

Pain at night-by shoulder

$(n=27) \quad(n=27)$

1.4

$12 \quad 1.0$

Tenderness - by shoulder $(n=27)$

0.1

0.2

0.2

$\begin{array}{llll}24 & 0.2 & 0.2 & 0.60\end{array}$

$(n=27)$

$1.6 \quad 0.61$

$\begin{array}{ll}1.6 & 0.72 \\ 1.5 & 0.09\end{array}$

$1.5 \quad 0.09$

$1.4 \quad 0.03$

$(n=28)$

$0.4 \quad 0.012$

$0.5 \quad 0.017$

$0.4 \quad 0.18$

Change from baseline in abduction range of motion-by shoulder

$$
(\mathrm{n}=27) \quad(\mathrm{n}=29)
$$

$\begin{array}{lll}2 & 7.7 & 1.5\end{array}$

$\begin{array}{lll}6 & 7.8 & 2.0 \\ 12 & 16.3 & 1.2\end{array}$

$\begin{array}{lll}24 & 26.6 & 8.7\end{array}$

Change from baseline in adduction power-by shoulder

$\begin{array}{lll} & (\mathrm{n}=27) & (\mathrm{n}=28 \\ 2 & 5.6 & 1.3\end{array}$

$\begin{array}{ll}2 & 5.6 \\ 6 & 7.7 \\ 12 & 11.9\end{array}$

9.9

0.32

$-0.6 \quad 0.08$

0.11

Change from baseline in external rotation power-by shoulder

$(n=27) \quad(n=28)$

$\begin{array}{lll}4.7 & 0.5 & 0.17 \\ 7.4 & 0.8 & 0.11\end{array}$

$\begin{array}{lll}7.4 & 0.8 & 0.11\end{array}$

$\begin{array}{llll}12 & 11.5 & 0.5 & 0.023 \\ 24 & 13.4 & 0.3 & 0.013\end{array}$

Change from baseline in external rotation range of motion-by shoulder

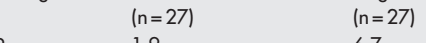

$\begin{array}{lll}2 & 1.9 & 6.7\end{array}$

$6 \quad 4.7 \quad 7.7$

$12 \quad \begin{array}{lll}7.7 & 3.3 & 0.26\end{array}$

Change from baseline in forward flexion-by shoulde

$(n=36) \quad(n=41)$

$\begin{array}{lll}2 & 7.8 & 0.8 \\ 6 & 6.5 & -2.3\end{array}$

$\begin{array}{lll}12 & 13.4 & -2.2\end{array}$

$24 \quad 20.3 \quad 6.3$

Impingement external rotation (\% with 0$)-$ by shoulder
\[ (\mathrm{n}=27) \quad(\mathrm{n}=28) \]

$\begin{array}{lll}2 & 40.7 & 32.1\end{array}$

32.1
57.1

$\begin{array}{ll}70.4 & 57.1 \\ 70.4 & 50.0\end{array}$

mpingement internal rotation (\% with 0$)$-by shoulder

$(\mathrm{n}=27) \quad(\mathrm{n}=2$

$33.3 \quad 10.7$

17.9

$51.9-32.1$

39.3

0.15
0.29

0.020

004

0.24

11

\subsection{2}

0.45

0.26

0.11

0.09

0.019

0.027

0.51

0.57

0.36

0.15

74.1

power-by shoulder

Change from baseline in internal rotation pow $\quad(n=28)$
\[ (n=27) \quad(4.9) \]

\begin{tabular}{|c|c|c|c|}
\hline & $(n=27)$ & (n $=28$ & \\
\hline 2 & 4.9 & -0.9 & 0.14 \\
\hline 6 & 10.8 & 2.0 & 0.055 \\
\hline 12 & 11.0 & -1.5 & 0.029 \\
\hline 24 & 13.9 & 1.1 & 0.01 \\
\hline \multicolumn{4}{|c|}{$\begin{array}{l}\text { Change from baseline in internal rotation range of motion-by shoulder } \\
\qquad(n=27) \\
\qquad(n=28)\end{array}$} \\
\hline 2 & -2.3 & 0.5 & 0.37 \\
\hline 6 & -4.3 & -1.0 & 0.22 \\
\hline 12 & -5.0 & 0.6 & 0.15 \\
\hline 24 & -8.1 & -0.3 & 0.32 \\
\hline
\end{tabular}

GTN patches were applied to the area of maximal tenderness once a day. Both the patients and the clinical examiner were blinded as to which group the patients were in. In each trial, the patients also received education and exercises - that is, the GTN treatment was on top of "best practice". The results of these trials can be found in Paoloni et al. ${ }^{18-20}$

Dr Eugene Heyman completed an independent reanalysis of the data from the three studies. In this analysis any missing data, whenever it occurred, were filled in by carrying forward the last value. Each analysis was adjusted for the baseline value. For categorical data with responses of $0-4$, the baseline value was treated as a block - that is, all the patients with a baseline value of 0 were grouped together, those with a baseline of 1 were grouped together and so on. The mean results were then compared between treatment groups within each baseline score and then
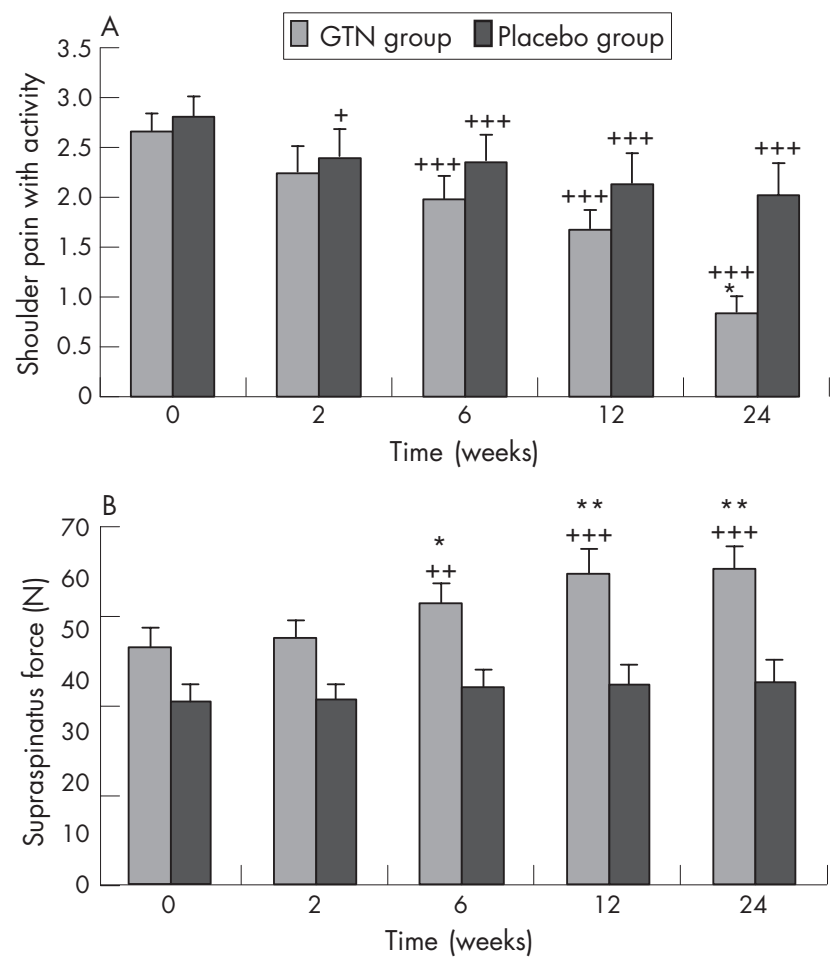

Figure 3 Supraspinatus tendinosis. Effects of glyceryl trinitrate (GTN, $\mathrm{n}=28$ ) $1.25 \mathrm{mg} / \mathrm{d}$ via transdermal patch versus rehabilitation alone (placebo, $\mathrm{n}=29$ ) on shoulder pain with activities (A) and on dynamometermeasured supraspinatus force (B); a between-groups comparison of means and the standard error of the mean. Significant differences: ${ }^{*} p<0.05$, ${ }^{* *} \mathrm{p}<0.01 .{ }^{++} \mathrm{p}<0.01,{ }^{+++} \mathrm{p}<0.001$ compared with baseline using student's paired $t$ tests. (Adapted from Paoloni et $a^{R O}$ ). 


\section{What this study adds}

- This study, involving three clinical trials, showed that delivering nitric oxide via a patch enhances clinical recovery of tendinopathy in humans.

- The enhancement is manifested by a reduction in pain, an increase in range of motion and an increase in strength.

\section{What is already known on this topic}

- Nitric oxide (NO) is important to tendon healing.

- Nitric oxide synthase (NOS) activity is upregulated in tendinopathy.

- In animal models where NOS activity is inhibited, tendon healing is reduced.

- When additional NO is added, tendon healing is enhanced.

the treatment differences were averaged while using the total number of patients within the baseline category to weight the results. Patients within the same baseline score were treated the same, but the treatment differences were weighted by the total number of patients within that baseline score. For continuous data (eg, total work), the change from baseline was used and then included as a covariate to account for any baseline differences and to account for the relationship between the baseline and the change from baseline. When patients with bilateral data were identified, the data were analysed in three ways. First, the results from the two sides were averaged, then, all bilateral patients were excluded. Finally, each group was treated separately. Tables 1-4 presents the results.

\section{TENNIS ELBOW}

The NO group had less tenderness and could perform more work and had greater peak power on the Orthopaedic Research Institute-Ankle Strength Testing System testing (table 2). The changes were most apparent at week 24 . In all, $81 \%$ of patients receiving GTN patches were asymptomatic in activities of daily living at 6 months compared with $60 \%$ of patients with tendon rehabilitation alone $\left(\mathrm{p}=0.005\right.$ with $\chi^{2}$ analysis $) .{ }^{19}$

\section{ACHILLES TENDONITIS}

The NO (GTN) group performed significantly better on hop testing and could generate more peak force at week 24 (table 3 ). In all, $78 \%$ of patients receiving GTN patches were asymptomatic for activities of daily living at 6 months compared with $49 \%$ of patients with tendon rehabilitation alone $(p=0.001$ with $\chi^{2}$ analysis). The mean effect size for all outcome measures was $14 \%{ }^{18}$

\section{SUPRASPINATUS TENDINOPATHY}

This trial produced the most significant effects. The NO group had significantly reduced shoulder pain with activity and at night, improved range of motion in abduction, forward flexion and external rotation, and improved power in abduction, external rotation, subscapularis and supraspinatus (table 4). ${ }^{20}$ The changes in supraspinatus power were the most dramatic, and were significant at 6 weeks (table 4, fig 3). In all, $46 \%$ of patients receiving GTN patches were asymptomatic for activities of daily living at 6 months compared with $24 \%$ of patients with tendon rehabilitation alone $(p=0.007)$. The mean effect size of GTN treatment for all outcome measures was $26 \%{ }^{20}$

\section{DISCUSSION}

NO is important to tendon healing. All three isoforms of NOS, the enzyme that produces NO, are expressed by fibroblasts during tendon healing. Our data in animal studies, cell culture and clinical trials support the hypothesis that $\mathrm{NO}$ enhances extracellular matrix synthesis and results in injured tendons having better material and mechanical properties-that is, the healing tendons are stronger on a per unit area basis than those not exposed to additional NO. The clinical trials show that delivering NO via a patch enhances the clinical recovery of tendinopathy, which is manifested by a reduction in pain, an increase in range of motion and an increase in strength.

\section{ACKNOWLEDGEMENTS}

I thank the following for their invaluable contributions: Tom Best, Allison Collins, Ed Lilly, Anthony Seaber, Richard Goldner, Kim Hayes, Judie Walton, Zoltan Szomor, Jian-Hao Lin, Min Wang, Ai Wei, Wei Zhu, Ashish Diwan, Danny Jang, Xian-Hao Deng, Jo Hannafin, Helen Davies, Marty Dolan, Dedee Murrell, Richard Appleyard, Janice Nelson, Fiona Bonar, Gong-Yao Tang, Jun Yuan, Piero Del Soldato, Wei Zhu, Wei Xia, Yao Wang, Denis King, James Urbaniak, Martin Francis, Robert Duthie, Ed Puzas, Charles Turner, Chris Evans, Bruce Caterson, Csaba Szabo, Laura Manfield, Justin Paoloni, Tim Molloy, Eugene Heyman, Robert Ang, National Institutes of Health Grant AR42729 (GACM), the Soft Tissue Research Fund, Piedmont Foundation, Orthopaedic Research and Education Foundation (OREF), St George Private Hospital/Health Care of Australia and St George Hospital/South East Health, and NiCOX Corporation and Cure Therapeutics.

Competing interests: None declared.

\section{REFERENCES}

1 Palmer RMJ, Ashton DS, Moncada S. Vascular endothelial cells synthesize nitric oxide from L-arginine. Nature 1988;333:664-6.

2 Bredt DS, Hwang PM, Snyder SH. Localization of nitric oxide synthase indicating a neural role for nitric oxide. Nature 1990;347:768-70.

3 Stuehr DJ, Nathan CF. Nitric oxide: a macrophage product responsible for cytostasis and respiratory inhibition in tumor target cells. J Exp Med 1989;169:1543-55.

$4 \mathrm{Xie}$ QW, Cho HJ, Calaycay J, et al. Cloning and characterization of inducible nitric oxide synthase from mouse macrophages. Science 1992;256:225-8.

5 Murrell GAC, Szabo C, Hannafin JA, et al. Modulation of tendon healing by nitric oxide. Inflamm Res 1997:46:19-27.

6 Lin J-H, Wang M-X, Wei A, et al. Temporal expression of nitric oxide synthase isoforms in healing Achilles tendon. J Orthop Res 2001;19:136-42.

7 Lin J-H, Wang M-X, Wei A, et al. The cell specific temporal expression of nitric oxide synthase isoforms during Achilles tendon healing. Inflamm Res 2001;50:1-8.

8 Szomor ZL. Nitric oxide in rotator cuff tendon [PhD thesis]. Sydney: University of New South Wales, 2003.

9 Carpenter JE, Flanagan CL, Thomopoulos S, et al. The effects of overuse combined with intrinsic or extrinsic alterations in an animal model of rotator cuff tendinosis. Am J Sports Med 1998;26:801-7.

10 Carpenter JE, Thomopoulos S, Flanagan CL, et al. Rotator cuff defect healing: a biomechanical and histologic analysis in an animal model. J Shoulder Elbow Surg 1998;7:599-605.

11 Szomor Z, Appleyard RA, Murrell GAC. Overexpression of nitric oxide synthases in tendon overuse. 49th Annual Meeting of the Orthopaedic Research Society. New Orleans, LA, 2003:146.

12 Szomor ZL, Wang MX, Kruller A, et al. Differential expression of cytokines and nitric oxide synthase expression in human rotator cuff bursae. Ann Rheum Dis $2001 ; 60: 431-2$

13 Xia W, Wang Y, Appleyard R, et al. Achilles tendon healing in iNOS knockout mice. 49th Annual Meeting of the Orthopaedic Research Society, New Orleans, LA. 2003:824.

14 Xia W, Szomor Z, Wang Y, et al. Nitric oxide enhances collagen synthesis in cultured human tendon cells. J Orthop Res 2006;24:159-72.

15 Molloy TJ, de Bock C, Wang Y, et al. Gene expression changes in SNAPstimulated and iNOS-transfected tenocytes-expression of extracellular matrix genes and its implications for tendon healing. J Orthop Res 2006;24:1869-82.

16 Tang GY, Murrell GAC, Yuan J, et al. Addition of NO via NO-paracetamol enhances collagen content and organization of healing rat Achilles tendon. Proceedings of the 50th Annual Meeting of the Orthopaedic Research Society, New Orleans, LA. 2004:876

17 Yuan J, Murrell GAC, Wei AQ, et al. Addition of nitric oxide via nitroflurbiprofen enhances the material properties of healing Achilles tendon. Inflamm Res 2003;52:230-7.

18 Paoloni J, Appleyard R, Murrell GAC. A randomized double-blind placebo controlled clinical trial investigating the use of topical nitric oxide application in the treatment of Achilles tendonitis. J Bone and Joint Surg (Am) 2004;86-A:916-22.

19 Paoloni JA, Appleyard RC, Nelson J, et al. Topical nitric oxide application in the treatment of chronic extensor tendinosis at the elbow: a randomized, doubleblinded, placebo-controlled clinical trial. Am J Sports Med 2003;31:915-20.

20 Paoloni JA, Appleyard RC, Nelson J, et al. Topical glyceryl trinitrate application in the treatment of chronic supraspinatus tendinopathy: a randomized, doubleblinded, placebo-controlled clinical trial. Am J Sports Med 2005;33:806-13. 